\title{
Liquid Chromatography and Fourier Transform Infrared Spectroscopy for quantitative analysis of individual and total curcuminoid in Curcuma longa extract
}

\author{
Ratna Wulandari ${ }^{1,2}$, Sudjadi $^{1}$, Sudibyo Martono ${ }^{1}$, Abdul Rohman $^{1 *}$ \\ 'Department of Pharmaceutical Chemistry, Faculty of Pharmacy, Universitas Gadjah Mada, Yogyakarta, 55281, Indonesia. \\ ${ }^{2}$ The National Agency of Drug and Food Control, Republic of Indonesia.
}

\begin{tabular}{|c|c|}
\hline ARTICLE INFO & ABSTRACT \\
\hline $\begin{array}{l}\text { Article history: } \\
\text { Received on: } 11 / 03 / 2018 \\
\text { Accepted on: } 23 / 07 / 2018 \\
\text { Available online: } 30 / 09 / 2018\end{array}$ & $\begin{array}{l}\text { Analysis of individual and total curcuminoid composed of curcumin (CUR), desmethoxycurcumin (DMCUR) and } \\
\text { bisdemethoxycurcumin (BDMCUR) in Curcuma species is very important. Curcuminoids are frequently used as } \\
\text { markers in herbal medicine involving the use of Curcuma species in its formulation. The objective of this study was to } \\
\text { validate high-performance liquid chromatography (HPLC) and Fourier transform infrared spectroscopy-partial least } \\
\text { square (FTIR-PLS) for quantitative analysis of total and individual curcuminoids in turmeric (Curcuma longa L.) }\end{array}$ \\
\hline $\begin{array}{l}\text { Key words: } \\
\text { Curcuma longa Linn, } \\
\text { curcuminoid, partial least } \\
\text { square, HPLC, FTIR } \\
\text { spectroscopy. }\end{array}$ & $\begin{array}{l}\text { extract. The turmeric powder was macerated using ethanol and evaporated to obtain an ethanolic extract. The actual } \\
\text { contents of individual curcuminoids of CUR, DMCUR, and BDMCUR were determined using HPLC. FTIR-PLS can } \\
\text { be used for quantitative analysis of individual and total curcuminoids using specific wavenumbers. The coefficient of } \\
\text { determination }\left(\mathrm{R}^{2}\right) \text { for the relationship between actual values and FTIR-PLS predicted values for calibration, internal, } \\
\text { and external validation was }>0.98 \text { which indicated good accuracy. The relatively low values of errors in calibration, } \\
\text { validation and external validation indicated good precision. FTIR spectroscopy-PLS can be used as an alternative } \\
\text { technique over HPLC for determination of individual and total curcuminoid in turmeric extracts. }\end{array}$ \\
\hline
\end{tabular}

\section{INTRODUCTION}

The use of turmeric (Curcuma longa Linn) as a raw material in herbal medicines and food products has increased significantly (Liang et al., 2004; Gad et al., 2013). Because of its composition especially curcuminoid, turmeric is known as functional food components, turmeric has been reported to have antibacterial, antiinflammation, and antioxidant activities due to high contents of curcuminoid (Sing et al., 2002; De et al., 2009; Anubala et al., 2014), neuroprotective (Issuriya et al., 2014), immunomodulatory (Rogers et al., 2010), antidiabetic (Wickenberg et al., 2010), as well as antitumor and anticancer activities (Aggarwal et al., 2003; Wilken et al., 2011). Because of high antioxidant activities, turmeric has been widely used in cosmetics, nutraceuticals, and phytomedicines (Paulucci et al.,

\section{${ }^{*}$ Corresponding Author}

Abdul Rohman, Department of Pharmaceutical Chemistry, Faculty of Pharmacy, Universitas Gadjah Mada, Yogyakarta, 55281, Indonesia. E-mail:abdul_kimfar@ugm.ac.id
2013).

In order to assure the quality of herbal materials from one batch to other batches, it is important to determine the levels of chemical compounds responsible for the biological activities. Curcuminoid in turmeric, especially curcumin, has been used as a chemical marker during biological activity evaluation (Gupta et al., 1999). According to Indonesian Herbal Pharmacopeia, turmeric extract should contain minimum $33.90 \%$ of total curcuminoid with moisture content less than 10\% (Ministry of Health, 2008). Indeed, analytical techniques capable of quantifying curcuminoid (total and individual) should be developed.

Some analytical techniques have been developed and used for quantitative analysis of curcuminoid, namely thin layer chromatography-densitometry (Péret-Almeida et al., 2005), high performance liquid chromatography using ultraviolet-visible and electrochemistry detectors (Inoue et al., 2008; Syed et al., 2015), liquid chromatography-mass spectrometry (Asai and Miyazawa, 2000), and capillary electrophoresis (Jiang et al., 2006). Due to its capability to provide separation among components in 
samples, chromatography-based methods are a method of choice for analysis of multicomponent such as in extract; however, these methods are time-consuming and involving the use of excessive chemicals and reagents. Therefore, there is a need to develop analytical techniques capable of quantifying analytes using some simple methods based on spectroscopy such as near-infrared spectroscopy (Tanaka et al., 2008) and mid-infrared spectroscopy (Rohman et al., 2015).

Fourier transform infrared (FTIR) spectroscopy is promising techniques for the quantification of curcuminoid due to its capability to provide fast and green analytical technique, with minimum sample preparation step (Bunaciu et al., 2011; Rohman, 2012). Combined with multivariate calibration, FTIR spectroscopy can be used as an alternative technique for chromatographic techniques. Tanaka et al. (2008) have analyzed individual curcuminoid of curcumin (C), desmethoxycurcumin (DMC) and bisdemethoxycurcumin (BDMC) and total curcuminoid (as a sum of C + DMC + BDMC) using near infrared at 1650-1780 nm. In this study, mid-infrared $\left(4000-400 \mathrm{~cm}^{-1}\right)$ was used due to more peaks obtained, as consequence, the modeling of PLS using more peaks was more achievable (Bunacie et al., 2011). Rohaeti et al. (2015) using FTIR spectroscopy in combination with principal component analysis (PCA) and canonical variate analysis (CVA) for identification and classification of turmeric, temulawak (Curcuma xanthorhiza) and bengle (Zingiber cassumunar). In our best knowledge, there is no report regarding the application of FTIR spectroscopy for analysis of individual and total curcuminoid using HPLC and FTIR spectroscopy combined with PLS. In this research, the individual curcuminoid was isolated from the mixture using column chromatography and the isolated compounds obtained was used for quantification using HPLC and FTIR spectroscopy combined with PLS regression.

\section{MATERIALS AND METHODS}

Curcuminoid containing CUR, DMCUR and BDMCUR was purchased from E. Merck (Darmstadt, Germany) with curcuminoid contents $\geq 94 \%$. Turmeric was obtained from several regions of Java (East Java, Central Java, West Java, Yogyakarta, and Jakarta). The synthetic curcumin was kindly given by Prof. Dr. Sudibyo Martono from Department of Pharmaceutical Chemistry, Faculty of Pharmacy, Universitas Gadjah Mada, Indonesia. The solvents used for mobile phase were of HPLC grade. The other solvents and reagents were of pro-analytical grade unless otherwise was specified.

\section{Isolation of $\mathrm{C}$, DMC, and BDMC}

Isolation of curcuminoid (with curcuminoid contents $\geq 94 \%$ ) from E. Merck into CUR, DMCUR and BDMCUR was carried out according to Péret-Almeida et al. (2005) using column chromatography with stationary phase of silica gel 60 for column chromatography (230-400 mesh) (Merck, Darmstadt, Germany), with mobile phase of chloroform-methanol delivered in gradient manner. Each fraction obtained was subjected to TLC, and the fraction containing the same curcuminoid was compiled. The solvent was evaporated using a vacuum rotary evaporator, and the powder obtained was determined for its purity qualitatively using TLC with three different mobile phase systems. The purity of individual curcuminoids was also determined using HPLC with photodiode array detector at $425 \mathrm{~nm}$ using an internal normalization technique (relative percentage).

\section{Preparation of ethanolic extract of turmeric}

The samples of turmeric were cleaned from any dirty, cut into small using the commercial cutter, and dried using a conventional oven at $50^{\circ} \mathrm{C}$. The dried turmeric was powdered using a grinder and subjected to sieving using mesh 40. A-50 gram of powdered turmeric was subjected to maceration using $500 \mathrm{~mL}$ ethanol $90 \%$ in aquadest for 24 hours (Tanaka et al., 2008). The macerate was filtered and the supernatant was evaporated using a vacuum rotary evaporator at $50^{\circ} \mathrm{C}$ to obtain an ethanolic extract. The ethanolic extract was then fractionated using $n$-hexane two times, and the purified ethanolic extract was then added with amprotab (1 part extract:19 part amprotab) and subjected to FTIR spectroscopic measurement and HPLC analysis.

\section{HPLC analysis and validation}

The condition of HPLC was optimized based on Wichitnithad et al. (2009) to get the best separation among CUR, DMCUR, and BDMCUR. The final condition used during analysis of curcuminoid in ethanolic extract of turmeric was:

$\begin{array}{ll}\text { Column: } & \text { Waters X-bridge C18 }(250 \mathrm{~mm} \times \\ & 4.6 \mathrm{~mm} \text { i.d; } 5 \mu \mathrm{m}) \\ \text { Mobile phase: } & \begin{array}{l}\text { acetonitrile : acetic acid } 2 \% \text { in } \\ \text { aquadest }(50: 50 \mathrm{v} / \mathrm{v}) \text { delivered } \\ \text { isocratically at } 1.0 \mathrm{~mL} / \mathrm{min}\end{array} \\ & \text { PDA at } 425 \mathrm{~nm} \\ \text { Detector: } & 20 \mathrm{uL} \\ \text { Volume of injection: } & 30^{\circ} \mathrm{C}\end{array}$

\section{Validation of HPLC method}

The optimized HPLC condition was subjected to validation according to International Conference Harmonization (ICH, 2005) by assessing several parameters namely: selectivity, linearity and range, limit of Detection (LoD), limit of quantification, precision, and accuracy.

\section{FTIR spectroscopy analysis}

Analysis of ethanolic extract of turmeric added with amprotab was performed using the sampling technique of attenuated total reflectance (ATR) as in Rohman et al. (2015). The samples were directly placed on ATR crystal and its spectra were scanned using FTIR spectrophotometer ABB MB3000 (Clairet Scientific, Northampton, UK), equipped with deuterated triglycine sulfate (DTGS) detector and beam splitter of germanium, and processed using Horizon MB FTIR software version 3.0.13.1 (ABB, Canada). FTIR spectra were measured at mid-infrared (4000-650 $\mathrm{cm}^{-1}$ ) using a resolution of $4 \mathrm{~cm}^{-1}$ and number of scanning of 32. All spectra were rationed against a background of air spectrum. After every scan, a new reference air background spectrum was taken. These spectra were recorded as absorbance values at each data point in duplicate.

\section{Statistical analysis}

The analytical results obtained using HPLC was used 
as actual content values of CUR, DMCUR, and BDMCUR and were correlated with predicted values of CUR, DMCUR, and BDMCUR using PLS calibration. PLS is calibration model used to solve problems involving high collinearity or to calculate correlated $Y$ variables (Gad et al., 2013). PLS has been associated with other mathematical methods and algorithms, and the most used algorithms to implement PLS regression is non-linear iterative partial least squares (NIPALS). The concentration variables (y-axis) are related to the predictor variables (x-axis) through auxiliary variables known as latent variables (factors or components), which are linear combinations of the variables $x_{1}, x_{2}, \ldots, x_{K}$. These components are highly similar to principal components calculated by principal component analysis. Minitab software version 17 was used for statistical analysis during calibration, internal validation using leave one out technique, and external validation.

\section{RESULTS AND DISCUSSION}

The reference standard of CUR, DMCUR, and BDMCUR used for quantitative analysis was isolated from curcuminoid using column chromatography. The isolated compounds of CUR, DMCUR and BDMCUR were analyzed using TLC with three different polarity solvents. Figure 1 showed that CUR, DMCUR, and BDMCUR were well separated. Curcumin is the major component in curcuminoid and is obtained relatively easy compared to DMCUR and BDMCUR. The purity levels of CUR, DMCUR, and BDMCUR as determined using HPLC with a photodiode array detector at $425 \mathrm{~nm}$ were of $99.92 \%, 98.53 \%$ and $85.85 \%$, respectively.
(A)

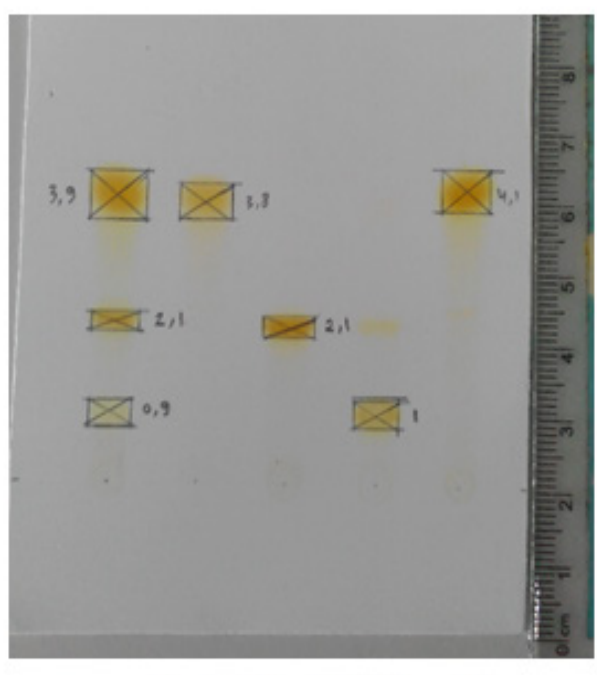

M C DMC BDMC SC
(B)

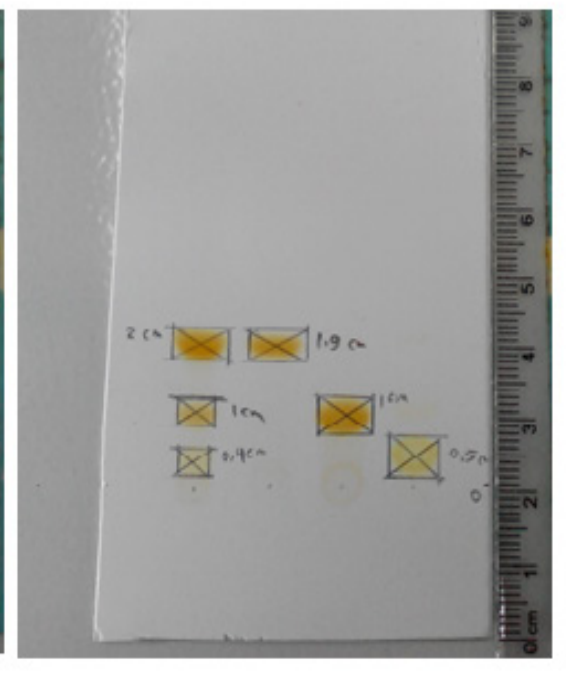

M C DMC BDMC
(C)

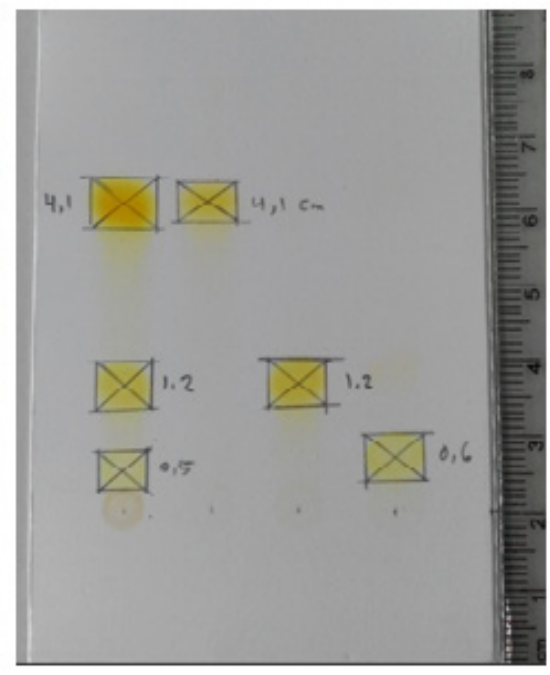

M C DMC BDMC

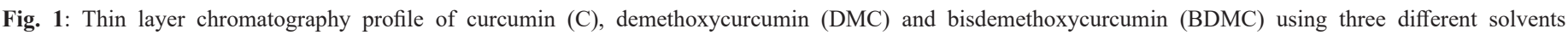

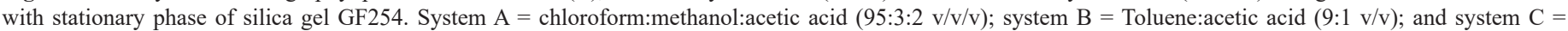
chloroform:aquadest:Ethanol (25:0.04:0.96). $\mathrm{M}=$ Curcuminoid; $\mathrm{SC}=$ synthetic curcumin.

Due to its versatility, high-performance liquid chromatography (HPLC) was the method of choice for determination of curcuminoid because curcuminoid is relatively non-polar and suitable to be separated using reversed HPLC column (Prabaningdyah et al., 2017). HPLC was reference method for quantitative analysis of CUR, DMCUR and BDMCUR in ethanolic extract of turmeric, and was optimized in order to meet the requirement of system suitability test, namely resolution $>2$; tailing factor $<1.8$ and number of theoretical plate $>10.000$. Two columns, namely Waters X-bridge C18 $(250 \mathrm{~mm} \times 4.6 \mathrm{~mm}$ i.d; $5 \mu \mathrm{m})$ and Waters Spherisorb, $\mathrm{C}_{18},(250 \times 4.6 \mathrm{~mm}, 5 \mu \mathrm{m})$ were compared, and finally Waters X-bridge $\mathrm{C} 18$ was chosen with mobile phase of acetonitrile:acetic acid $2 \%$ in aquadest (50:50 $\mathrm{v} / \mathrm{v}$ ) delivered isocratically at $1.0 \mathrm{~mL} / \mathrm{min}$. HPLC chromatogram of CUR, DMCUR, and BDMCUR obtained using optimum condition was shown in Figure 2. The elution order of curcuminoid was BDMCUR with $t_{R}$ of \pm 6.795 min, DMCUR with $t_{R}$ of \pm 7.43 min, and CUR with $t_{R}$ of \pm 8.130 min. This order was in agreement with the polarity of curcuminoid, in which BDMCUR is more polar than DMCUR and CUR.

\section{Validation of HPLC method for analysis of C, DMC, and BDMC}

HPLC was validated for quantitative analysis of CUR, DMCUR and BDMCUR in turmeric extract by determining several parameters namely selectivity, linearity, limit of detection, limit of quantification, accuracy, and precision according to International Conference on Harmonization (2005). The system suitability test indicated that HPLC system used was precise enough because the relative standard deviation (RSD) values of retention times and a peak area of CUR, DMCUR and BDMCUR from six replicates were less than $2.0 \%$. Besides, the resolution value (Rs) of $>2$, the number of a theoretical plate $(\mathrm{N})>10.000$, and tailing factor $(\mathrm{TF})$ $\leq 2$ were achieved as requested by United States Pharmacopeia.

The selectivity of HPLC for separation of curcuminoid was expressed with resolution value (Rs). The obtained Rs values 
of CUR, DMCUR and BDMCUR were 2.67, 2.59 and 15.56, respectively which indicated that the validated method was selective enough for separation of curcuminoid. The linearity of HPLC was assessed on concentration range of $0.4248-4.2484 \mu \mathrm{g} /$ $\mathrm{mL}$ for CUR, 0.3139-1.8835 $\mu \mathrm{g} / \mathrm{mL}$ for DMCUR, and 0.3288 $1.644 \mu \mathrm{g} / \mathrm{mL}$ for CUR. The correlation coefficient (r) obtained for the relationship between concentration of CUR, DMCUR and BDMCUR and peak area (y-axis) were 0.9995, 0.9996 and 0.9996 , with \%y-intercept values of $3.43 \%, 3.21 \%$ and $6.17 \%$, respectively. All r-values were higher than 0.999 indicating that the HPLC method was linear over the concentration range, which covers $50-150 \%$ from the target of analytes in the studied ethanolic extract of turmeric (ICH, 2005).

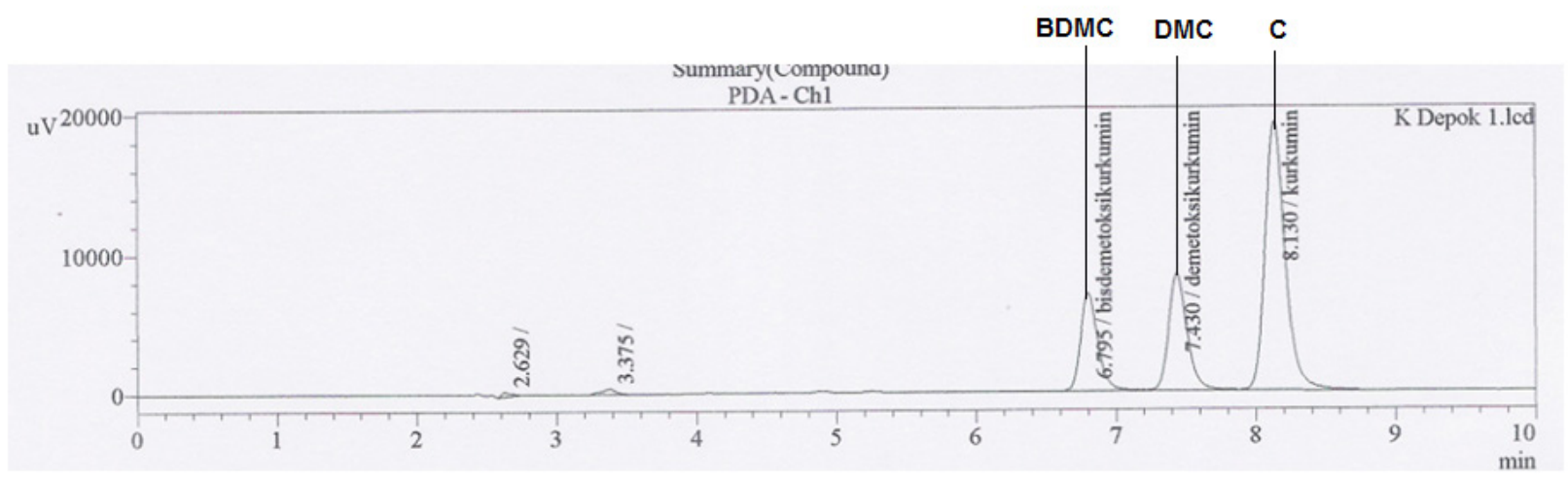

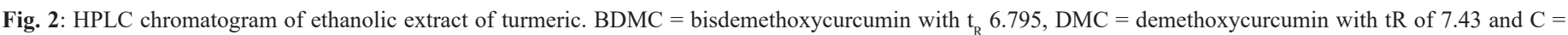

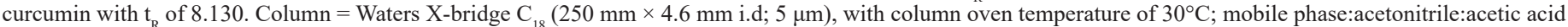
$2 \%$ in aquadest $(50: 50 \mathrm{v} / \mathrm{v})$ delivered isocratically at $1.0 \mathrm{~mL} / \mathrm{min}$; detector = photodiode array $(\mathrm{PDA})$ at $425 \mathrm{~nm}$.

The precision of developed HPLC was assessed by repeatability test and intermediate precision by analysis six replicates of homogeneous sample extract. RSD values of CUR, DMCUR, and BDMCUR were $1.34 \%, 1.42 \%$, and $3.45 \%$, respectively, lower than those requested by RSD Horwitz (i.e. $4 \%$ ) at a concentration level of $1 \%$ of target analytes (Gonzalez and Herrador, 2007). In addition, the recovery values for accuracy studies of CUR, DMCUR, and BDMCUR were studied by standard addition methods by spiking CUR, DMCUR, and BDMCUR into the turmeric extract samples. The recovery values obtained were $98.05-100.38 \%$ for CUR, $99.30-101.60 \%$ for DMCUR, and $99.97-100.0 \%$ for BDMCUR. These values are in agreement with those specified in ICH (2005).

The sensitivity of HPLC was expressed by determining the limit of detection (LoD) and limit of quantification (LoQ). The LoD and LoQ values obtained were $0.0040 \mu \mathrm{g} / \mathrm{mL}, 0.0037$ $\mu \mathrm{g} / \mathrm{mL}$, and $0.0049 \mu \mathrm{g} / \mathrm{mL}$ for CUR, DMCUR and BDMCUR, respectively, while LoQ values were $0.0162,0.0104$, and 0.0147 $\mu \mathrm{g} / \mathrm{mL}$ respectively. The values of LoD were confirmed by injecting these concentrations 5 times, and RSD of $23.55 \%$ was obtained indicating that $\mathrm{LoD}$ values were not precise enough to be used as LoQ. In addition, the reported LoD and LoQ values of CUR were lower than those reported by Dandekar and Patravale (2009), i.e. $0.06 \pm 0.01 \mu \mathrm{g} / \mathrm{mL}$ and $0.21 \pm 0.045 \mu \mathrm{g} / \mathrm{mL}$, respectively. However, $\mathrm{LoD}$ and $\mathrm{LoQ}$ values of this study were also lower (more sensitive) than those reported by Cheng et al. (2010) using ultra performance liquid chromatography (UPLC) with uv-vis detector. LoD and LoQ values were 0.040 and 0.134 $\mu \mathrm{g} / \mathrm{mL}$ for CUR, 0.049 and $0.164 \mu \mathrm{g} / \mathrm{mL}$ for DMCUR, as well as 0.029 and $0.098 \mu \mathrm{g} / \mathrm{mL}$ for BDMCUR, respectively.

The validated HPLC method was subsequently used for quantitative analysis of CUR, DMCUR, and BDMCUR in the samples, and the results were shown in Table 1. The concentrations of CUR, DMCUR, and BDMCUR and curcuminoid total obtained from HPLC analysis was used as actual values in PLS modeling during prediction of CUR, DMCUR and BDMCUR using FTIR spectroscopy.

Table 1: The concentration of curcumin (CUR), demethoxycurcumin (DMCUR) and bisdemethoxycurcumin (BDMCUR) in ethanolic extract of Turmeric obtained from Java region, Indonesia.

\begin{tabular}{ccccc}
\hline Region & CUR & DMCUR & BDMCUR & Curcuminoid total* \\
\hline Bandung (West java) & 1.56 & 0.51 & 0.94 & 3.01 \\
Jakarta & 1.17 & 0.34 & 0.60 & 2.11 \\
Cilacap (central Java) & 1.40 & 0.55 & 1.52 & 3.47 \\
Depok (west Java) & 1.41 & 0.58 & 0.89 & 2.88 \\
Magelang (central Java) & 1.20 & 0.46 & 1.01 & 2.67 \\
Bantul (Yogyakarta) & 1.68 & 0.61 & 1.02 & 3.31 \\
Karanganyar (central Java) & 1.61 & 0.52 & 0.96 & 3.09 \\
Kediri (East Java) & 1.88 & 0.52 & 0.89 & 3.29 \\
Kuningan (Jakarta) & 1.41 & 0.47 & 0.98 & 2.86 \\
Purworejo (central Java) & 1.05 & 0.33 & 0.62 & 2.00 \\
Sleman (Yogyakarta) & 1.41 & 0.55 & 1.29 & 3.25 \\
Sukaharjo (central Java) & 1.19 & 0.52 & 0.92 & 2.63 \\
Temanggung (central Java) & 1.37 & 0.61 & 1.17 & 3.15 \\
Wonogiri (central Java) & 0.76 & 0.29 & 0.52 & 1.57 \\
\hline
\end{tabular}

*Curcuminoid total is the sum of CUR + DMCUR and BDMCUR.

\section{Analysis using FTIR spectroscopy}

FTIR spectroscopy is taken into account as the fingerprint analytical technique used for qualitative and quantitative analyses of analyte(s) including Curcuma longa extracts (Prabaningdyah et al., 2018). To facilitate FTIR spectroscopy as quantitative analysis method of curcuminoid in ethanolic extract of turmeric, PLS was employed for making the correlation between actual content values of curcuminoid as determined using HPLC and FTIR predicted 
values using absorbance values at optimized wavenumbers. PLS is multivariate calibration technique based on inverse calibration in which concentration (y-axis) was modeled with factors (combination of absorbance variables) in the x-axis (Miller and Miller, 2005). Figure 3 exhibited FTIR spectra of ethanolic extract of turmeric from several regions of Java, scanned at wavenumbers of 4000-650 $\mathrm{cm}^{-1}$ along with main peaks corresponding to IR absorption at specific wavenumbers. All functional groups in Figure 3 were representative of those of curcuminoid. These peaks were in accordance with those reported by Rohman et al. (2015), Rohaeti et al. (2015) and Prabaningdyah et al. (2018).

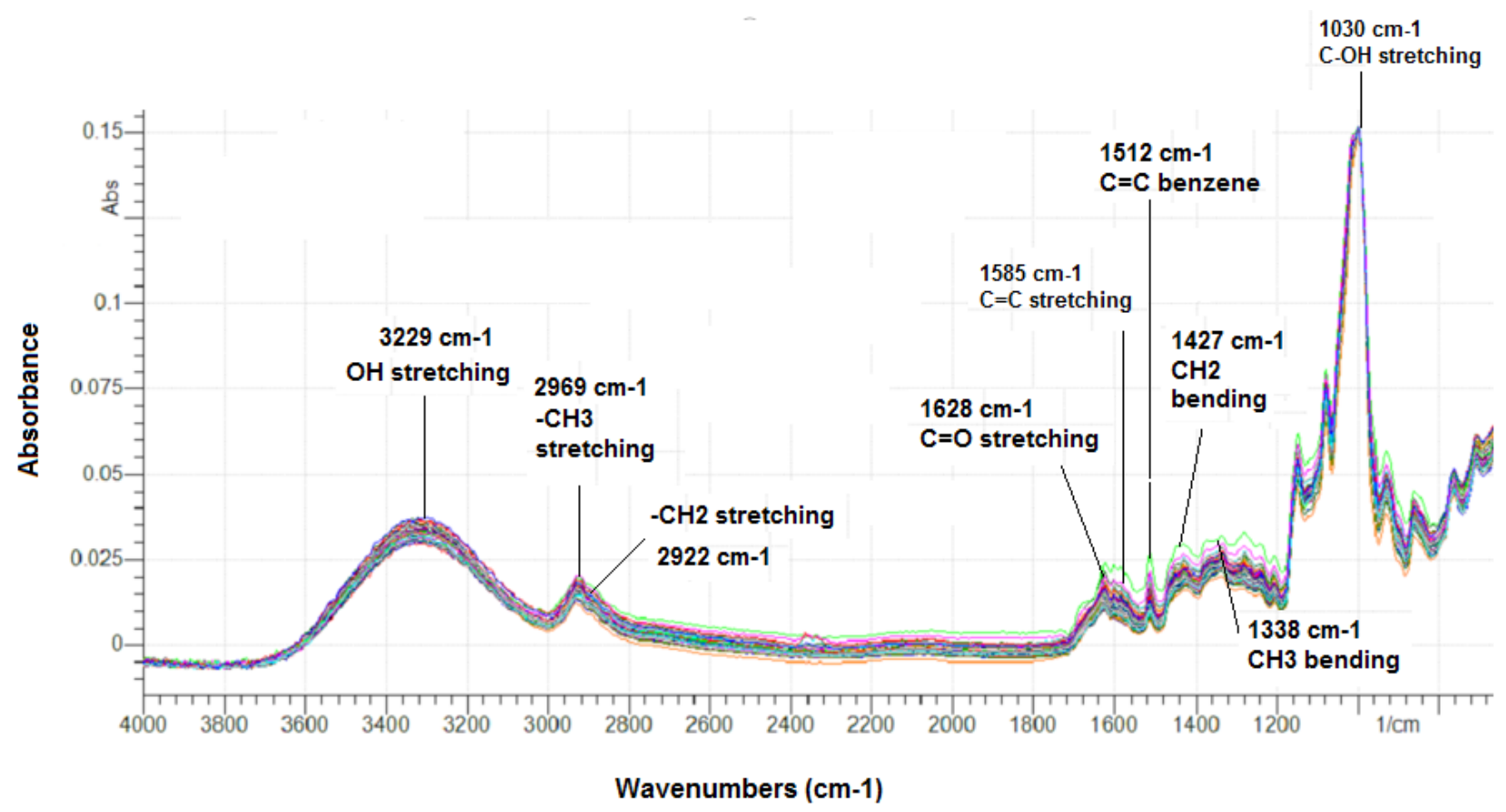

Fig. 3. FTIR spectra of ethanolic extract of turmeric from 14 regions of Java, scanned at mid-infrared region $\left(4000-650 \mathrm{~cm}^{-1}\right)$ along with main peaks corresponding to IR absorption at specific wavenumbers.

Analysis of curcuminoid with FTIR spectroscopy coupled with PLS calibration was performed in three steps, namely calibration, validation, and analysis of unknown samples. Before calibration modeling, FTIR spectra of all samples were subjected to optimization in order to get the best region capable of providing the acceptable correlation between actual values and FTIR predicted values of a curcuminoid and the lowest errors. Optimization was performed by selecting the wavenumbers region and spectral treatments (Lestari et al., 2017). Finally, the wavenumbers of $1400-1720 \mathrm{~cm}^{-1}$ were preferred for quantification of CUR, wavenumbers of 1481-1747 $\mathrm{cm}^{-1}$ used for quantitative analysis of DMCUR, the combined wavenumbers region of $1172-1226 \mathrm{~cm}^{-1}$ and $1469-1785 \mathrm{~cm}^{-1}$ used for analysis of BDMCUR, while the wavenumbers of $1407-1820 \mathrm{~cm}^{-1}$ were exploited for analysis of total curcuminoid. Figure 4 revealed the calibration model for the relationship between actual values of CUR, DMCUR, and BDMCUR and total curcuminoid and FTIR predicted values. The coefficient determination $\left(\mathrm{R}^{2}\right)$ obtained were 0.9998 (CUR), 0.9999 (DMCUR), 0.9996 (BDMCUR) and 0.9999 (total curcuminoid). The root mean square error of calibration (RMSEC) values obtained were $0.469,0.0035,0.0063$ and $0.064 \mathrm{mg} \%$ for CUR, DMCUR and BDMCUR and total curcuminoid, respectively. The high value of $\mathrm{R}^{2}$ and low values of RMSEC indicated that FTIR spectroscopy using these specific wavenumbers were accurate and precise for quantitative analysis of curcuminoid. From figure 4, it is clear that results obtained from HPLC were not significantly from those obtained by FTIR spectroscopy as indicated by the high $\mathrm{R}^{2}$ value.

PLS calibration model was further validated using leave one out (LOO) technique. In LOO, one of the calibration samples was removed from the calibration model, and the remaining samples were used to make new PLS model. Subsequently, the removed sample was computed using the new PLS regression model. This manner was recurred, leaving each sample out in turn. The difference between the actual values and calculated values of CUR, DMCUR, and BDMCUR and total curcuminoid was calculated (Miller and Miller, 2005). The validation models of $\mathrm{C}$, $\mathrm{DMC}, \mathrm{BDMC}$ and total curcuminoid during LOO resulting the predicted residual error sum of squares (PRESS) of $1.4 \times 10^{-6}$ for CUR, $2 \times 10^{-7}$ for DMCUR, $4.4 \times 10^{-6}$ for BDMCUR, and $2.6 \times$ $10^{-6}$ for total curcuminoid. The low values of PRESS indicated that the calibration model was precise enough to be used for analysis of CUR, DMCUR and BDMCUR, and total curcuminoid in unknown samples. However, based on results obtained during external validation, RMSEP values of DMCUR and BDMCUR was too high, therefore, the developed model was not used for prediction of DMCUR and BDMCUR.

Analysis of CUR and total curcuminoid in unknown samples from Sleman and Sukoharjo, central Java using FTIR spectroscopy with PLS calibration model was performed. The results obtained were compared with those obtained using HPLC using statistical Tukey test at a significance level of 0.05 . There was 
no significant difference of results obtained by FTIR spectroscopy and HPLC $(\mathrm{P}>0.05)$. The P values were 1.25 and 1.23 for CUR, as well as 3.25 and 2.63 for total curcuminoid of turmeric obtained from Sleman and Sukoharjo, respectively. FTIR spectroscopy combined with PLS calibration model offered alternative method over HPLC due to its simplicity and its capability to provide simultaneous analysis of curcuminoid without a separation step.
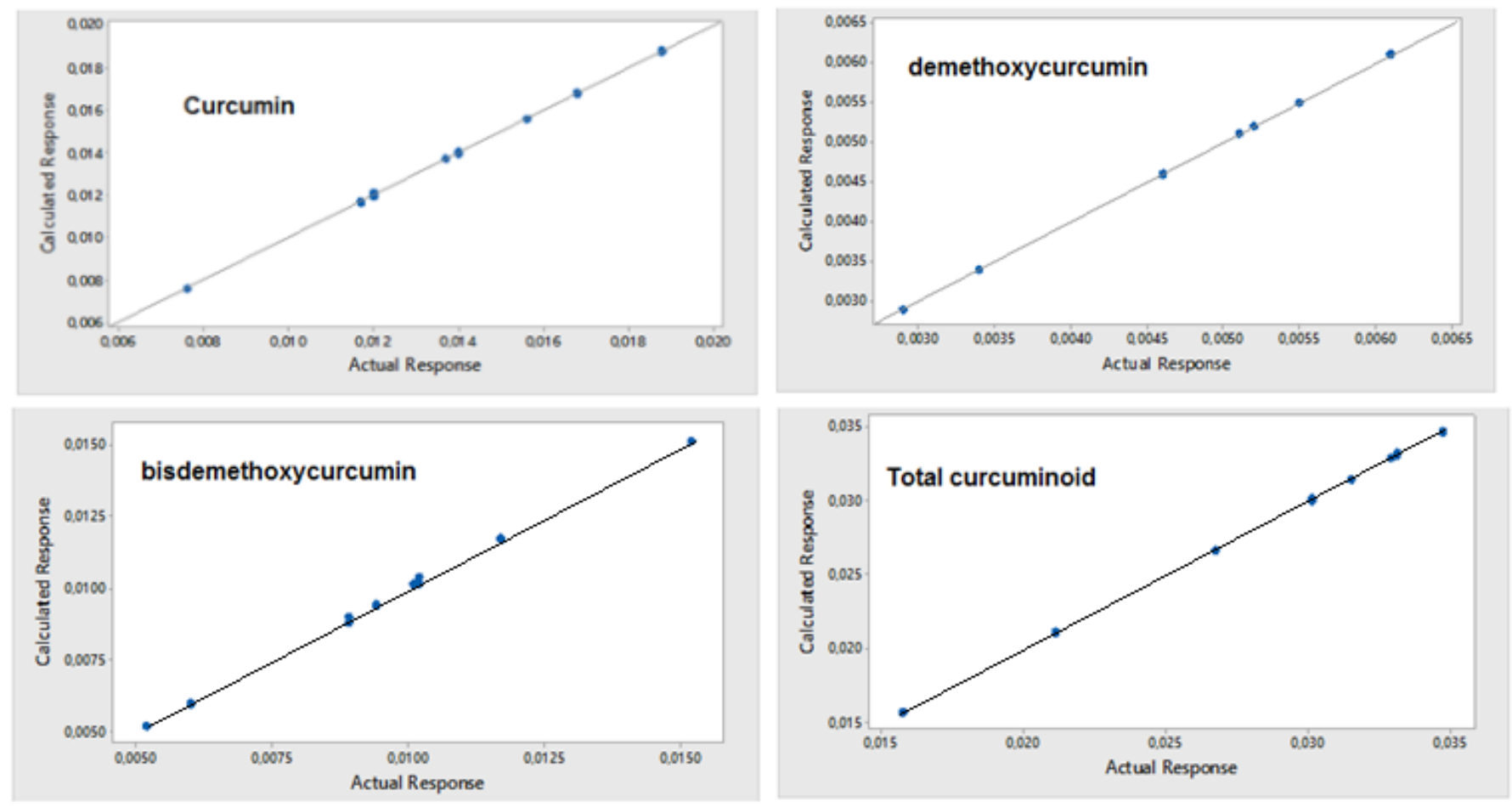

Fig. 4: PLS calibration model for the relationship between actual values of curcumin, demethoxycurcumin, bisdemethoxycurcumin and total curcuminoid with FTIR predicted/calculated values using specific wavenumbers.

\section{CONCLUSION}

FTIR spectroscopy combined with PLS calibration model is an alternative technique for HPLC due to the capability of FTIR spectroscopy-PLS to offer the close relationship between actual values as determined by HPLC and FTIR predicted values with low errors. CUR was determined at wavenumbers of the region of $1400-1720 \mathrm{~cm}^{-1}$, while total curcuminoid was analyzed at $1407-1820 \mathrm{~cm}^{-1}$. The $\mathrm{R}^{2}$ value for the correlation between actual values of a curcuminoid and FTIR-PLS was $>0.98$ indicating the accuracy of the method with low errors. FTIR spectroscopy is fast, not destructive and no excessive sample preparation.

\section{CONFLICT OF INTEREST}

The authors declared no conflict of interest.

\section{ACKNOWLEDGMENT}

The author thanks the Ministry of Research and Higher Education for financial support during this research via scheme Penelitian Unggulan Perguruan Tinggi 2016 with contract number 807/UN1-P.III/LT/DIT-LIT/2016.

\section{REFERENCES}

Aggarwal BB, Kumar A, Bharti AC. Anticancer potential of curcumin: Preclinical and clinical studies. Anticancer Res, 2003; 23:363398.
Anubala S, Sekar R, Nagaiah K. Development and validation of an analytical method for the separation and determination of major bioactive curcuminoids in Curcuma longa rhizomes and herbal products using non-aqueous capillary electrophoresis. Talanta, 2014; 123:10-17.

Asai A, Miyazawa T. Occurrence of orally administered curcuminoid as glucuronide and glucuronide/sulfate conjugates in rat plasma. Life Sci, 2000; 67:2785-2793.

Bunaciu AA, Aboul-Enein HY, Fleschin S. Recent Applications of Fourier Transform Infrared Spectrophotometry in Herbal Medicine Analysis. Appl Spectros Rev, 2011; 46:251-260.

Cheng J, Weijun K, Yun L, Jiabo W, Haitao W, Qingmiao L, Xiaohe X. Development and validation of UPLC method for quality control of Curcuma longa Linn.: Fast simultaneous quantitation of three curcuminoids. J Pharm Biomed Anal, 2010; 53:43-49.

De R, Kundu P, Swarnakar S, Ramamurthy T, Chowdhury A, Nair GB, Mukhopadhyay AK. Antimicrobial Activity of Curcumin against Helicobacter pylori Isolates from India and during Infections in Mice. Antimicrob Agents Chemother, 2009; 53:1592-1597.

Gad HA, El-Ahmady SH, Abou-Shoer MI, Al-Azizi MM. Application of chemometrics in authentication of herbal medicines: A review. Phytochem Anal, 2013; 24:1-24.

González AG, Herrador MÁ. A practical guide to analytical method validation, including measurement uncertainty and accuracy profiles. TrAC Trends Anal Chem, 2007; 26:227-238.

Gupta AP, Gupta MM, Kumar S. Simultaneous Determination of Curcuminoids in Curcuma Samples Using High Performance Thin Layer Chromatography. J Liq Chromatogr Related Technol, 1999; 22:1561-1569. Inoue $\mathrm{K}$, Nomura $\mathrm{C}$, Ito $\mathrm{S}$, Nagatsu A, Hino $\mathrm{T}$, Oka $\mathrm{H}$. 
Purification of curcumin, demethoxycurcumin, and bisdemethoxycurcumin by high-speed countercurrent chromatography. J Agric Food Chem, 2008; 56:9328-9336.

International Conference on Harmonisation. Validation of Analytical Procedures: Text and Methodology. 2005; Retrieved from http:// www.ich.org/products/guidelines.html.

Issuriya A, Kumarnsit E, Wattanapiromsakul C, Vongvatcharanond U. Histological studies of neuroprotective effects of Curcuma longa Linn. on neuronal loss induced by dexamethasone treatment in the rat hippocampus. Acta Histochemica, 2014; 116:1443-1453.

Jiang H, Somogyi A, Jacobsen NE, Timmermann BN, Gang DR. Analysis of curcuminoids by positive and negative electrospray ionization and tandem mass spectrometry. Rapid Comm Mass Spectrom, 2006; 20:1001-1012.

Lestari HP, Martono S, Sudjadi, Rohman A. Simultaneous analysis of Curcumin and demethoxycurcumin in Curcuma xanthorriza using FTIR spectroscopy and chemometrics. Int Food Res J, 2017; 24(5):2097-2101.

Liang YZ, Xie P, Chan K. Quality control of herbal medicines. J Chromatogr B, 2004; 812:53-70.

Miller JN, Miller JC. 2005. Statistics and Chemometrics for Analytical Chemistry. $5^{\text {th }}$ Ed. Edinburgh: Pearson Education Limited.

Dandekar PP, Patravale VB. Development and Validation of a Stability-Indicating LC Method for Curcumin. Chromatographia, 2009; 69:871-877.

Paulucci VP, Couto RE, Teixeira CCC, Freitas LAP. Optimization of the extraction of curcumin from Curcuma longa rhizomes. Brazilian J Pharmacog, 2013; 23:94-100.

Péret-Almeida L, Cherubino APF, Alves RJ, Dufossé L, Glória MBA. Separation and determination of the physico-chemical characteristics of curcumin, demethoxycurcumin and bisdemethoxycurcumin. Food Res Int, 2005; 38:1039-1044.

Prabaningdyah NK, Riyanto S, Rohman A, Siregar C. Application of HPLC and response surface methodology for simultaneous determination of curcumin and desmethoxy curcumin in Curcuma syrup formulation. J App Pharm Sci, 2017; 7:58-64.

Prabaningdyah NK, Riyanto S, Rohman A. Application of FTIR spectroscopy and multivariate calibration for analysis of curcuminoid in syrup formulation. J App Pharm Sci, 2018; 8:172-179.

Rogers NM, Kireta S, Coates PTH. Curcumin induces maturation-arrested dendritic cells that expand regulatory $\mathrm{T}$ cells in vitro and in vivo. Clin Exp Immun, 2010; 162:460-473.

Rohaeti E, Rafi M, Syafitri UD, Heryanto R. Fourier transform infrared spectroscopy combined with chemometrics for discrimination of Curcuma longa, Curcuma xanthorrhiza and Zingiber cassumunar. Spectrochim. Acta Part A: Mol Biomol Spectros, 2015; 137:1244-1249.

Rohman A. Application of Fourier Transform Infrared Spectroscopy for Quality Control of Pharmaceutical Products: A Review. Indonesian J Pharm, 2012; 23:1-8.

Rohman A, Sudjadi D, Ramadhani D, Nugroho A. Analysis of Curcumin in Curcuma longa and Curcuma xanthorriza Using FTIR Spectroscopy and Chemometrics. Res J Med Plant, 2015; 9:179-186.

Singh R, Chandra R, Bose M, Luthra PM. Antibacterial activity of Curcuma longa rhizome extract on pathogenic bacteria. Current Sci, 2002; 83:737-740.

Syed HK, Liew KB, Loh GOK, Peh KK. Stability indicating HPLC-UV method for detection of curcumin in Curcuma longa extract and emulsion formulation. Food Chem, 2015; 170:321-326.

Tanaka K, Kuba Y, Sasaki T, Hiwatashi F, Komatsu K. Quantitation of curcuminoids in curcuma rhizome by near-infrared spectroscopic analysis. J Agric Food Chem, 2008; 56:8787-8792.

The Ministry of Health, Republic of Indonesia. 2008. Indonesian Herbal Pharmacopeia. $1^{\text {st }}$ Ed. Jakarta: Kemenkes.

Wichitnithad W, Jongaroonngamsang N, Pummangura S, Rojsitthisak P. A simple isocratic HPLC method for the simultaneous determination of curcuminoids in commercial turmeric extracts. Phytochem Anal, 2009; 20:314-319.

Wickenberg J, Ingemansson SL, Hlebowicz J. Effects of Curcuma longa (turmeric) on postprandial plasma glucose and insulin in healthy subjects. Nutr J, 2010; 9:1-5.

Wilken R, Veena MS, Wang MB, Srivatsan ES. Curcumin: A review of anti-cancer properties and therapeutic activity in head and neck squamous cell carcinoma. Mol Cancer, 2011; 10:1-19.

How to cite this article:

Wulandari R, Sudjadi, Martono S, Rohman A. Liquid Chromatography and Fourier Transform Infrared Spectroscopy for quantitative analysis of individual and total curcuminoid in Curcuma longa extract. J App Pharm Sci, 2018; 8(09): 107-113. 